\title{
Counterexample to Euler's Conjecture for Seventh Power
}

\section{Arij Zulfi Mufassaroh \& Adib Rifqi Setiawan}

A direct computer search yielded:

$$
127^{7}+258^{7}+266^{7}+413^{7}+430^{7}+439^{7}+525^{7}=568^{7}
$$

as the counterexample to a conjecture proposed by Leonhard Euler in 1679 that at least $n n$th powers are required to sum to an $n$th power, $n>2$ (Singh, 2017, p. 213; Nahin, 2011, p. 350).

\section{Reference}

Nahin, P. J. (2011). Dr. Euler's Fabulous Formula: Cures Many Mathematical Ills. Princeton University Press.

Singh, S. (2017). Fermat's Enigma: The Epic Quest to Solve the World's Greatest Mathematical Problem. Knopf Doubleday Publishing Group. 